\title{
Pemanfaatan material cork untuk desain kemasan parfum
}

\author{
Melatitanica Arkarima, ${ }^{1 *}$ Mochamad Junaidi Hidayat ${ }^{2}$ \\ ${ }^{1,2}$ Jurusan Desain Produk, Institut Teknologi Adhi Tama Surabaya, Surabaya, Indonesia
}

\begin{abstract}
Cork is an environmentally friendly material, has unique properties and characteristics, but in Indonesia Cork is only used as a material coaster and Cork Board products. Therefore, there appears an idea to develop a product of perfume packaging with cork material, because the perfume packaging is only box-shaped and cylinder. In this study, the collection of data used is by means of surveys and interviews, and assisted with supporting data such as secondary data (books, journals, Internet). Case studies conducted on this research conducted on five objects, namely PT. Grafika Prima Sejahtera, CV. Mulia Jaya Box, PT. Universal artwork, Cote De Azuro perfume Store and Victoria's Secret perfume Shop. The analysis used is an experimental analysis, before analyzing the design of competitors ' bottles and perfume packaging as part of the experimental step, researchers divided several stages of the experiment, the material stage, the coloring stage, Management stage, finishing stage, form experiment and material mix. Concept used is the concept of duplicate, namely following the form of perfume bottles and iconic, namely using the shape icons of women's body, to show perfume used in women. The duplicate concept is used on brands such as Bleau De Chanel perfume, Chanel Chance Women, Silver Babe Park Lane and Victoria's Secret. Iconic concept used on brand perfume Bvlgari Omnia. Researchers made 5 design alternatives, 4 with duplicate and 1 concepts with iconic concepts.
\end{abstract}

Key words: cork, design, packaging, perfume

\begin{abstract}
Abstrak
Cork merupakan material yang ramah lingkungan, memiliki sifat dan karakteristik yang unik, namun di Indonesia Cork hanya digunakan sebagai material produk coaster dan cork board. Sehingga dari situ muncul sebuah ide untuk mengembangkan produk kemasan parfum dengan material cork, karena kemasan parfum hanya berbentuk kotak dan silinder. Dalam penelitian ini, pengumpulan data yang digunakan yaitu dengan cara survey dan wawancara, serta dibantu dengan datadata pendukung seperti data sekunder (buku, jurnal, internet). Studi kasus yang dilakukan pada penelitian ini dilaksanakan pada lima objek, yaitu PT. Grafika Prima Sejahtera, CV. Mulia Jaya Box, PT. Universal Karya Artistik, Toko Parfum Cote De Azuro dan Toko Parfum Victoria's Secret. Analisis yang digunakan adalah analisis eksperimen, sebelumnya peneliti menganalisis desain botol dan kemasan parfum kompetitor sebagai bagian dari langkah eksperimen, peneliti membagi beberapa tahap pada eksperimen, tahap olah material, tahap pewarnaan, tahap pemolaan, tahap finishing, eksperimen bentuk dan mix material. Konsep yang digunakan adalah konsep duplicate, yaitu mengikuti bentuk botol parfum dan iconic, yaitu menggunakan ikon bentuk tubuh wanita, untuk menunjukkan parfum digunakan pada wanita. Konsep duplicate digunakan pada merk parfum Bleau De Chanel, Chanel Chance Women, Silver Babe Park Lane dan Victoria's Secret. Konsep iconic digunakan pada merk parfum Bvlgari Omnia. Peneliti membuat 5 alternatif desain, 4 dengan konsep duplicate dan 1 dengan konsep iconic.
\end{abstract}

Kata kunci: cork, desain, kemasan, parfum

\section{Pendahuluan}

Cork adalah penutup suberous (suberose parenchyma, atau kulit kayu) dari spesies Quercus
Suber L., umumnya dikenal sebagai cork oak. Cork adalah salah satu bahan baku alami paling serbaguna yang dikenal. Cork adalah bahan yang sangat ringan, elastis dan fleksibel serta tidak tembus terhadap gas

* Corresponding author e-mail : melati.titan@gmail.com 
atau cairan, bahkan sebagai bahan untuk isolator listrik yang tahan lama dan baik, isolator termal, suara dan getaran serta bahan dielektrik. Sebagai bahan seluler, sifatnya yang unik timbul dari struktur selnya yang tertutup (Gil, 2009).

Cork atau gabus, lebih familiar sebagai bahan bulletin board atau wine stopper. $\quad 70 \%$ produksi cork di dunia digunakan untuk memproduksi wine stopper dan hanya $22 \%$ yang digunakan untuk memproduksi bahan bangunan. Padahal material ini adalah material yang sangat ramah lingkungan, dari proses panennya, produksinya, hingga penggunaannya. (https://diyfabcolab.com/2018/09/14/material-007cork-si-material-ramah-lingkungan/)

World Wildlife Fund (WWF), organisasi konservasi lingkungan dunia pada web resminya menyatakan bahwa memanen kulit pohon cork oak adalah proses yang ramah lingkungan, dimana tidak ada pohon yang ditebang. Kulit pohon yang dipanen akan kembali tumbuh dan keberadaan pohon juga berarti menjaga kehidupan ekosistem di dalam montados. Sedangkan material sintetis lebih berbahaya bagi lingkungan karena menggunakan lebih banyak energi dalam produksi.(https://www.wwf.org.uk/updates/futurecork-oak-forests-hangs-balance.)

Penggunaan material cork yang ada di Indonesia selain digunakan sebagai material coaster (tatakan gelas) pada PT.Universal Karya Artistik (UNIART) juga dapat ditemukan pada produk IKEA. Pada produk IKEA, material cork hanya digunakan sebagai produk papan pengingat kegiatan sehari-hari atau disebut dengan cork board untuk penempelan tempat pengingat atau penempelan note.

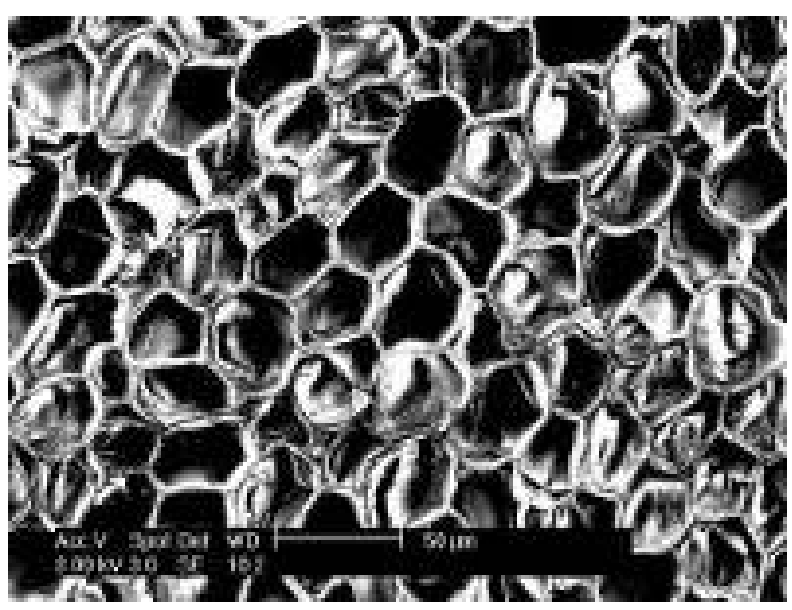

Gambar 1.1 Cork Celluler Structure (Sumber: Luis Gil, 2009)
Pemilihan pengembangan material cork menjadi produk kemasan parfum dikarenakan kemasan parfum hanya memiliki bentuk-bentuk kemasan kotak dan silinder yang sederhana. (Damai, 2010) Padahal beberapa parfum memiliki harga yang terbilang cukup murah yaitu puluhan ribu rupiah hingga yang sangat mahal yaitu puluhan juta rupiah, sehingga kemasan parfum seharusnya memiliki bentuk-bentuk yang lebih unik atau bisa menjadi salah satu branding untuk kemasan pada parfum itu sendiri. Kemasan parfum juga dapat dijadikan sebagai salah satu branding. Pemilihan penggunaan material cork sebagai kemasan parfum juga didukung oleh sifat dan karakteristik yang dimiliki oleh material cork yang sangat ringan, elastis dan fleksibel serta tidak tembus terhadap gas atau cairan, karena itu sangat sesuai untuk digunakan sebagai material kemasan parfum. Material ini juga biasa digunakan sebagai salah satu material digital printing dengan memanfaatkan teknologi laser, mampu menghasilkan bentuk yang estetik dan mampu menghasilkan gambar-gambar yang lebih menarik dibandingkan dengan kertas atau kardus yang menggunakan teknologi digital printing, karena itu diharapkan penelitian eksperimen yang dilakukan oleh peneliti dengan menggunakan material cork agar kemasan parfum lebih unik serta menarik dan mampu menjadi branding pada kemasan parfum itu sendiri.

Kemasan dapat didefinisikan sebagai seluruh kegiatan merancang dan memproduksi wadah atau bungkus atau kemasan suatu produk. Kemasan meliputi tiga hal, yaitu merek, kemasan itu sendiri dan label. Ada tiga alasan utama untuk melakukan pembungkusan, yaitu (Hidayat, 2009), (1) Kemasan memenuhi syarat keamanan dan kemanfaatan. Kemasan melindungi produk dalam perjalanannya dari produsen ke konsumen. Produk-produk yang dikemas biasanya lebih bersih, menarik dan tahan terhadap kerusakan yang disebabkan oleh cuaca. (2) Kemasan dapat melaksanakan program pemasaran. Melalui kemasan identifikasi produk menjadi lebih efektif dengan sendirinya mencegah pertukaran oleh produk pesaing. Kemasan merupkan satu-satunya cara perusahaan membedakan produknya. Dan (3) Kemasan merupakan suatu cara untuk menghubungkan produsen dengan konsumen (aspek komunikasi termasuk didalamnya meningkatkan laba perusahaan). Oleh karena itu perusahaan harus membuat kemasan semenarik mungkin. Dengan kemasan yang sangat menarik diharapkan dapat memikat dan menarik perhatian konsumen. Selain itu, kemasan juga dapat mengurangi kemungkinan kerusakan barang dan kemudahan dalam pengiriman. 


\section{Bahan dan metode}

Eksperimen adalah observasi di bawah kondisi buatan (artificial condition) di mana kondisi tersebut dibuat dan diatur oleh si peneliti. Sedangkan penelitian eksperimental adalah penelitian yang dilakukan dengan mengadakan manipulasi terhadap objek penelitian serta adanya kontrol. (Nazir, 2013)

Penelitian ini menggunakan penelitian jenis eksperimen, yaitu melakukan berbagai macam cara pengolahan pada material cork hingga menjadi bahan material utama untuk pembuatan sebuah produk berupa kemasan parfum melalui serangkaian rencana eksperimen, yaitu mulai dari pemilahan, pemotongan, laminasi, pewarnaan, pengeringan warna, pembentukan pola, penyatuan pola, finishing hingga proses eksperimen bentuk dan mix material pada material cork. Peneliti mencoba menggambarkan alur penelitian dalam memecahkan masalah di dalam metodologi desain, namun hal ini bukanlah menjadi tahap-tahap penelitian, tetapi dasar bagi peneliti untuk menerapkan tahap-tahap penelitian. Yang akan dilakukan dengan pemilihan secara teliti di setiap proses dan terdokumentasi untuk kemudian disimpulkan sebagai hasil eksperimen.

Pengambilan data melalui data primer dengan cara survey perusahaan kemasan yang memproduksi kemasan parfum sebagai objek pertama, yaitu PT.Grafika Prima Sejahtera, perusahaan kemasan yang memproduksi kemasan untuk botol kaca sebagai objek kedua, yaitu CV.Mulia Jaya Box, perusahaan yang bergerak dalam bidang Industri Kreatif dengan memanfaatkan teknologi laser dan zund sebagai objek penelitian material cork sebagai objek ketiga, yaitu PT.Universal Karya Artistik (UNIART), dua toko parfum yang ada di Plaza Gresik dan Tunjungan Plaza Surabaya sebagai objek keempat dan kelima, dengan cara wawancara, peneliti berkomunikasi secara langsung dengan karyawan dan staff yang bertugas pada kelima objek studi kasus, dengan cara dokumentas, pengambilan data oleh peneliti dengan cara mengambil gambar atau mendokumentsikan yang diperlukan untuk memperoleh data-data yang menunjang penelitian dan diperlukan untuk mengetahui proses produksi kemasan parfum. Pengambilan data melalui data sekunder sebagai data pendukung yang dibutuhkan peneliti untuk mendukung proses perancangan pemanfaatan material cork untuk desain kemasan parfum.

Metode penelitian selanjutnya adalah pengolahan data berasal dari data sekunder dan data primer sebagai dasar analisis desain dengan menggunakan botol parfum dan kemasan parfum dari beberapa merk kompetitor sebagai bagian langkah eksperimen. Pada tahap ekserimen dilakukan secara terukur dan terencana, peneliti melakukan beberapa tahapan proses eksperimen, mulai dari proses pemilahan, pemotongan, laminasi, pewarnaan, pengeringan warna, pembentukan pola, penyatuan pola, finishing hingga proses eksperimen bentuk dan mix material pada material cork.

Setelah tahap eksperimen dilakukan, tahap selanjutnya peneliti menganalisis dari hasil eksperimen dan dipilih eksperimen mana yang sesuai dalam penelitian ini, yaitu dengan menggunakan analisis eksperimen. Selanjutnya peneliti mengambil kesimpulan dari hasil analisis eksperimen yang telah dilakukan dan memungkinkan dipakai dalam pembuatan produk sebagai sintesis desain dan menentukan konsep desain dari judul "Pemanfaatan material cork untuk desain kemasan parfum” dan hasil sintesis desain yang akan digunakan sebagai alternatif desain hingga final desain akhir dan merupakan desain terpilih. Produk akan dibuat berdasarkan final desain akhir atau merupakan desain yang terpilih. Untuk mengetahui respon masyarakat dan uji coba terhadap produk yang telah dibuat, peneliti melakukan tahap diseminasi yang akan dilaksanakan pada pameran Despro ITATS ke-14 (empatbelas).

\section{Hasil dan pembahasan}

Gambar 2 memperlihatkan mapping eksperimen yang dilakukan oleh penulis.

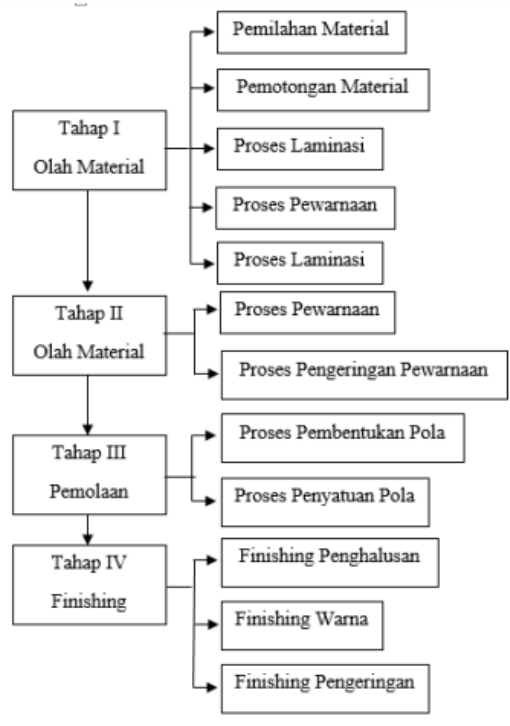

Gambar 2. Mapping eksperimen 
Berdasarkan mapping yang telah dibuat, dan eksperimen yang telah dilakukan oleh peneliti, maka diperoleh hasil seperti tampak pada Tabel 1, 2, 3, 4, dan 5 .

Tabel 1. Proses Eksperimen (1)

\section{Proses Eksperimen}

Pemilihan Material
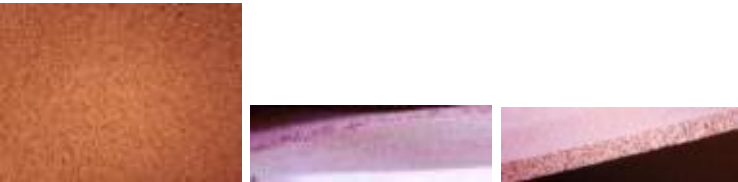

Proses pemilahan material dilakukan untuk memperoleh material yang memungkinkan untuk digunakan dan mempermudah proses selanjutnya (pemotongan dan pembentukan pola). Menggunakan material cork dengan butiran yang kecil dan ketebalan $2 \mathrm{~mm}$ dan $5 \mathrm{~mm}$

\section{Pemotongan Material}
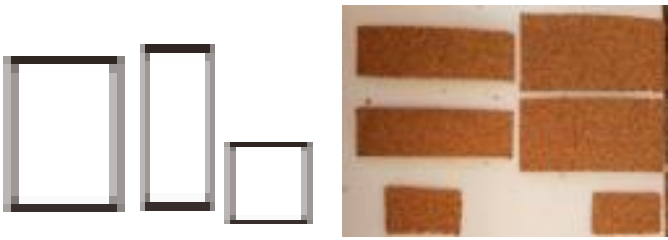

Proses pemotongan material dilakukan untuk menentukan layout setiap sisi dan ukuran yang dibutuhkan untuk kemasan parfum yang ingin di bentuk, sebelum proses laminasi. Menggunakan mal yang dibuat pada komputer dan harus dicetak terlebih dahulu. Menggunakan bentuk mengikuti bentuk botol parfum untuk merk Bleau De Chanel, Chanel Chance Women, Silver Babe Park Lane dan Victoria's Secret atau bentuk iconic untuk merk Bvlgari Omnia.

\section{Laminasi}
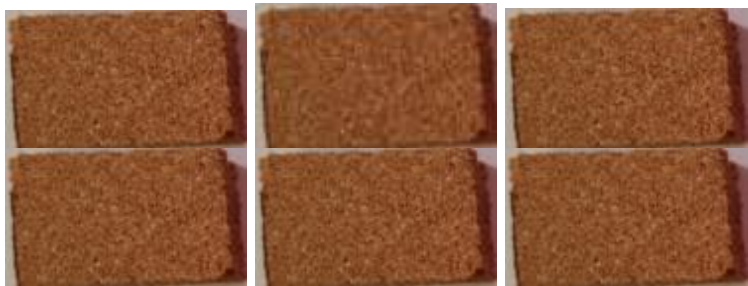

Proses laminasi dilakukan untuk memperkuat dan mempertebal material cork, proses laminasi 4 lapis pada material cork dengan ketebalan $2 \mathrm{~mm}$ dan proses laminasi 2 lapis pada material cork dengan ketebalan $5 \mathrm{~mm}$.
Tabel 2. Proses Eksperimen (2)

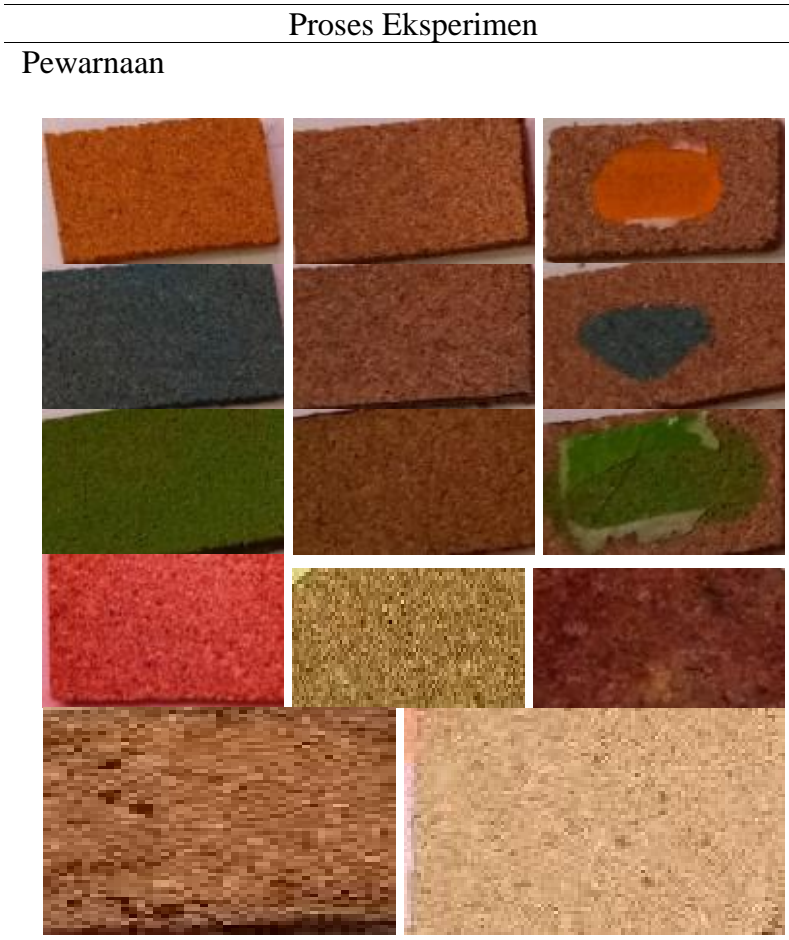

Proses pewarnaan dilakukan untuk memberikan warna pada material cork. Menggunakan cat poster, cat kertas dan cat tembok dengan teknik kuas, karena menghasilkan warna yang merata serta mempercepat proses pewarnaan.

Menggunakan warna yang sesuai aroma atau botol parfum

a. Bleau De Chanel: hitam

b. Chanel Chance Women: pink

c. Silver Babe Park Lane: abu - abu

d. Bvlgari Omnia: ungu

e. Victoria's Secret: pink - hitam

\section{Proses Pengeringan Warna}
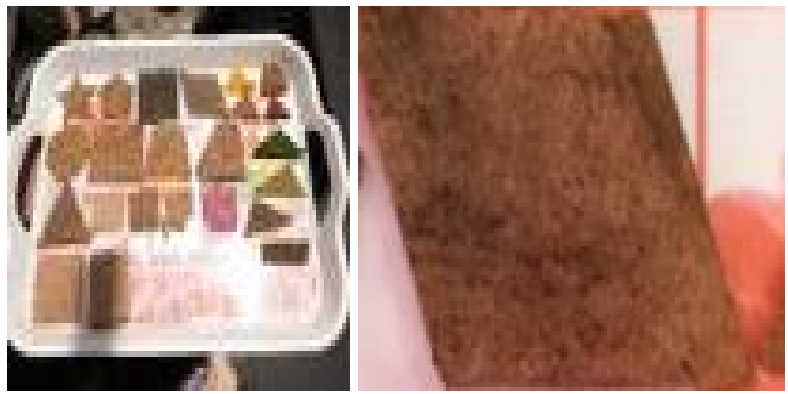

Proses pengeringan warna dilakukan agar material cork tidak berjamur setelah proses pewarnaan, pengeringan menggunakan sinar matahari selama 2 jam (pukul 12.00 14.00) dengan suhu $32^{\circ} \mathrm{C}$. 
Melatitanica Arkarima, Mochamad. Junaidi Hidayat

Pemanfaatan material cork untuk desain kemasan parfum

Tabel 3. Proses Eksperimen (3)

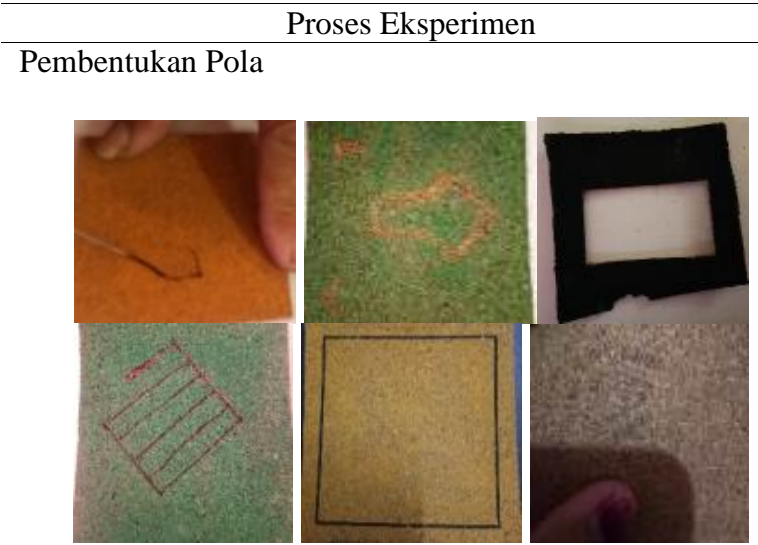

Proses pembentukan pola dilakukan untuk menghasilkan pola pada permukaan material cork, dengan cara dilubangi, solder dan laser, karena menghasilkan pola yang unik serta dapat di bentuk sesuai kebutuhan dan keinginan, tidak memakan waktu yang lama.

a. Menggunakan tulisan mengikuti jenis font merk parfum

Bleau De Chanel: sans serif

Chanel Chance Women: sans serif

Silver Babe Park Lane: script

Bvlgari Omnia: serif

Victoria's Secret: serif

b. Meletakkan brand parfum pada bagian tengah kemasan

c. Meletakkan nama produk parfum pada bagian tengah kemasan

d. Memberikan ornamen yang simple menggunakan unsur bentuk dan garis atau mengikuti brand merk parfum

e. Memberikan tekstur pada nama/logo produk parfum

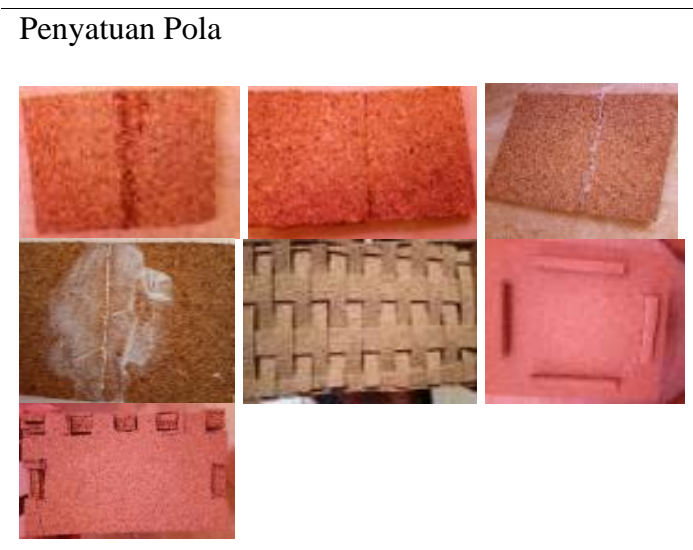

Proses penyatuan pola dilakukan untuk menyatukan pola satu dengan pola lainnya, sehingga dapat menjadi kemasan, menggunakan lem aibon, lem kayu, pola mortis tenon dan pola box join, karena menghasilkan penggabungan pola yang unik, tidak menghasilakan bekas pada material cork dan mempermudah proses penggabungan.
Tabel 4. Proses Eksperimen (4)

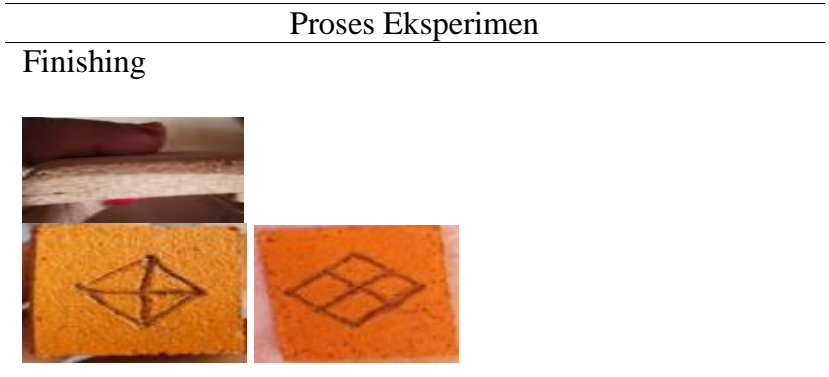

Proses finishing dilakukan untuk menghasilkan permukaan material cork yang lebih halus dan mengkilap, proses finishing penghalusan harus dilakukan agar menghasilkan bentuk material yang lebih rapi, menggunakan amplas halus 240, agar tidak mengikis terlalu banyak permukaan material cork. Proses finishing warna menggunakan clear dan vernish. Namun, untuk vernish, lebih digunakan untuk warna yang natural, karena memerlukan waktu yang lama untuk pengeringan finishing vernish pada material cork yang diberikan warna dan proses pengeringan finishing menggunakan sinar matahari untuk mempercepat proses pengeringan, sehingga pengeringan menggunakan kipas angin dapat dilakukan saat tidak ada sinar matahari.

Eksperimen Bentuk

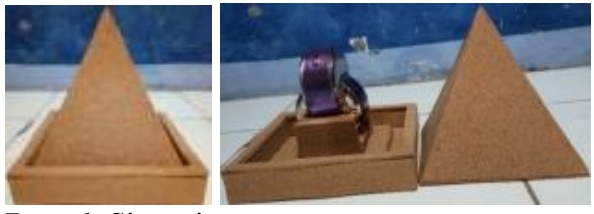

Bentuk Simetris

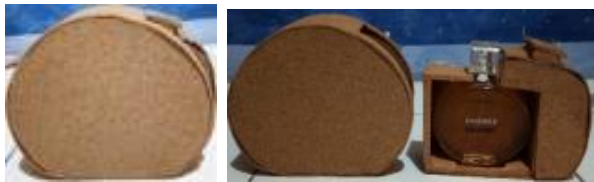

Bentuk Asimetris

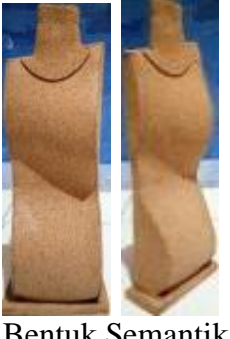

Bentuk Semantik 
Tabel 5. Proses Eksperimen (5)

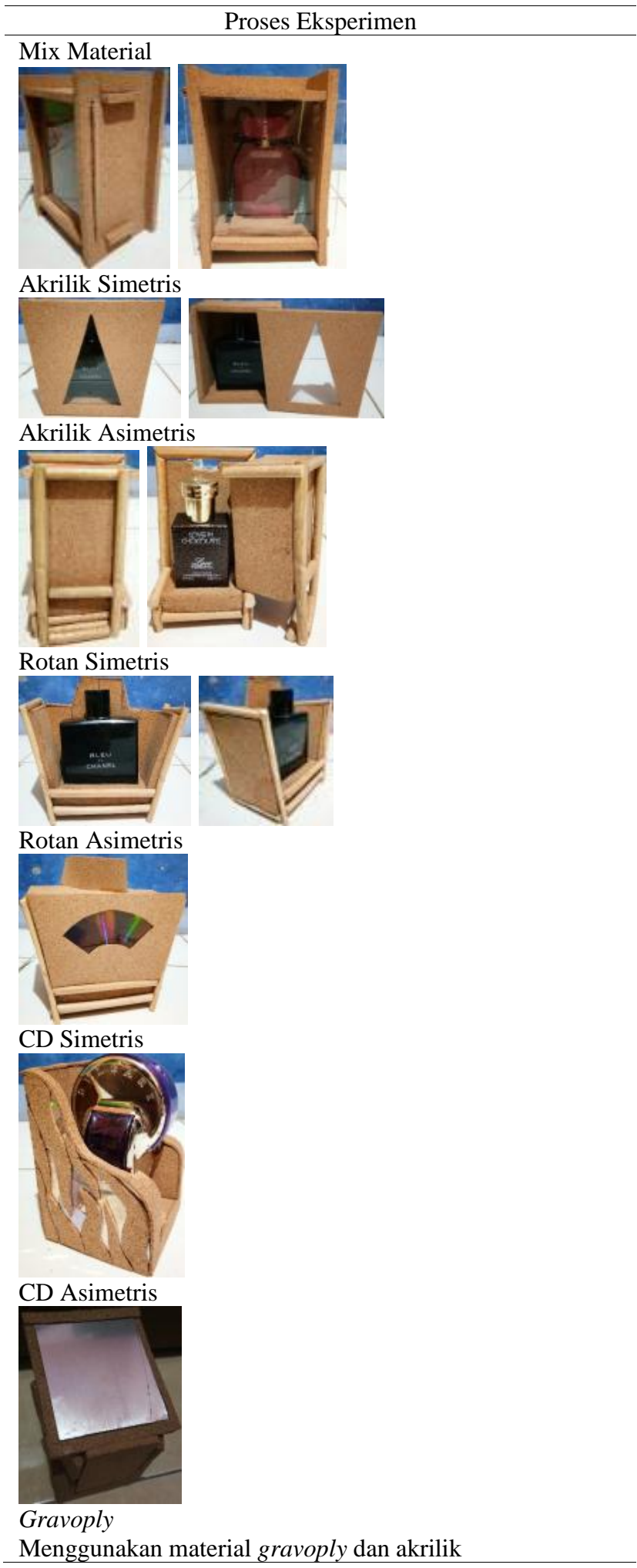

Konsep desain yang akan dipakai dalam penelitian ini adalah duplicate, menurut Jubilee Enterprise (2018), Duplicate atau duplikasi adalah membuat duplikat dari sebuah objek dengan sangat cepat. Konsep Duplicate pada produk kemasan parfum ini berarti menduplikasi dan mengikuti bentuk pada botol parfum. Jika bentuk botol parfum kotak, maka bentuk primer kemasan berbentuk kotak mengikuti bentuk botol parfum, namun dapat dikombinasikan dengan bentuk lain sebagai bentuk sekunder untuk menambah kesan estetika pada bentuk kemasan. Konsep ini digunakan pada produk kemasan dengan merk Bleau De Chanel, Chanel Chance Women, Silver Babe Park Lane dan Victoria's Secret.

Konsep iconic, dalam Kamus Besar Bahasa Indonesia (KBBI) iconic atau ikonis berkaitan dengan gambar atau lambang yang langsung menimbulkan pertalian dengan benda yang dilambangkannya. Konsep iconic pada produk kemasan parfum ini berarti menggunakan icon pada wanita, karena guna melambangkan parfum yang digunakan untuk wanita. Misal dapat menggunakan bentuk tubuh (body) pada wanita, atau menambah ornamen - ornamen aksesoris pada wanita. Konsep ini digunakan pada produk kemasan dengan merk Bvlgari Omnia.

\section{Alternatif Desain}

Alternatif Desain 1 (Bleau De Chanel). Desain yang digunakan pada alternatif desain 1 ini menggunakan bentuk kombinasi persegi dan trapesium dengan penutup geser pada bagian depan menggunakan material akrilik. Eksperimen yang digunakan yaitu pewarnaan menggunakan cat tembok water base berwarna hitam dan finishing menggunakan clear. Kemasan di kombinasikan dengan material gravoply pada bagian sisi samping kanan dan kiri (Gambar 3).

Alternatif Desain 2 (Chanel Chance Women). Desain yang digunakan pada alternatif desain 2 menggunakan bentuk setengah lingkaran dengan sistem buka tutup pada bagian samping dengan mix material menggunakan material gravoply yang di laser. Eksperimen yang digunakan yaitu pewarnaan menggunakan cat tembok water base berwarna pink dan finishing menggunakan clear (Gambar 4).

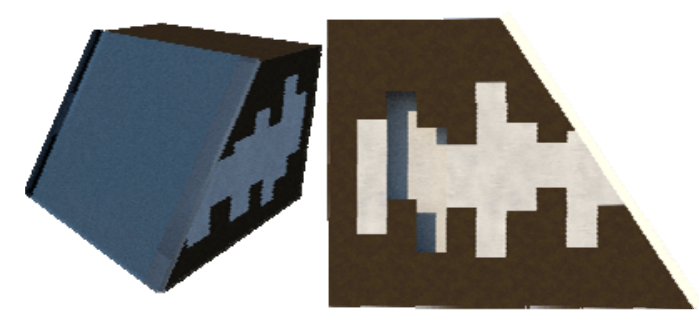

Gambar 3. Alternatif Desain 1 


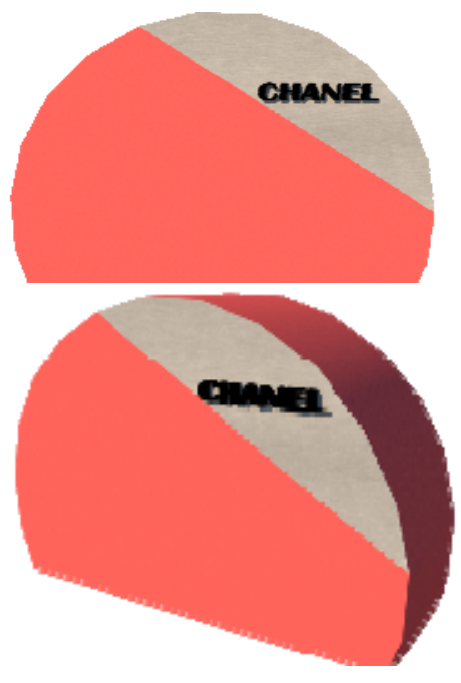

Gambar 4. Alternatif Desain 2
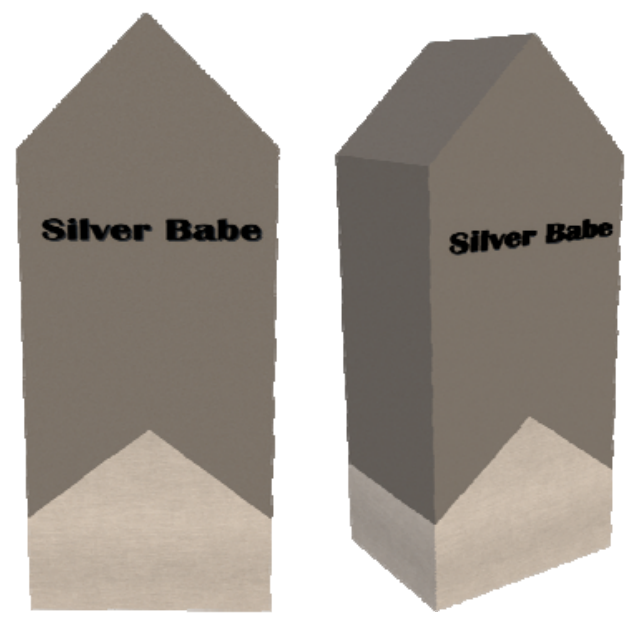

Gambar 5 Alternatif Desain 3

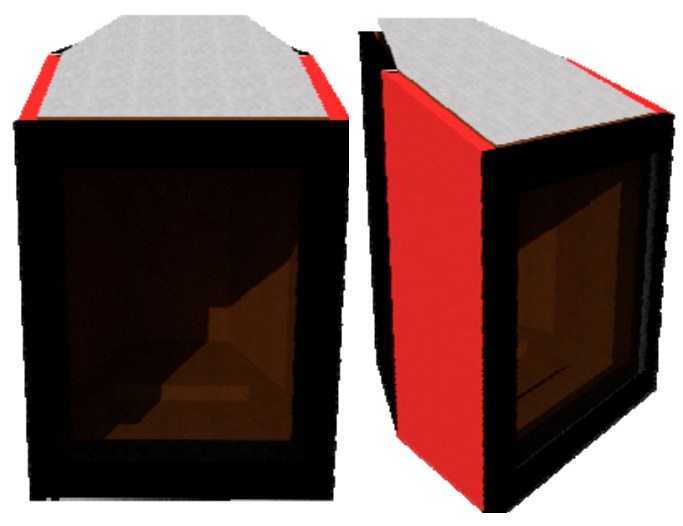

Gambar 6 Alternatif Desain 4

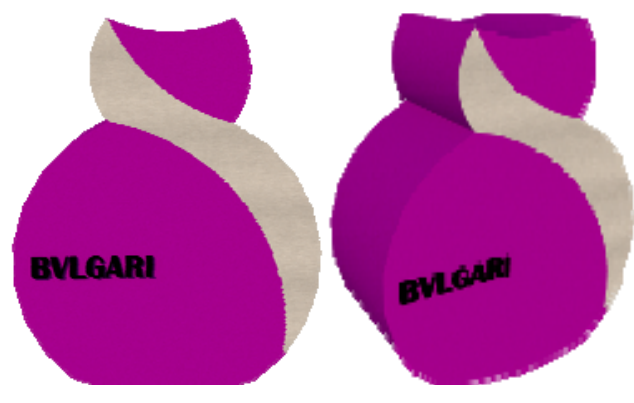

Gambar 7 Alternatif Desain 5

Alternatif Desain 3 (Park Lane). Desain yang digunakan pada alternatif desain 3 menggunakan bentuk kombinasi persegi dan segitiga dengan sistem buka tutup pada bagian atas (Gambar 5). Eksperimen yang digunakan yaitu laser pada bagian merk dan pewarnaan menggunakan cat tembok water base berwarna abu - abu serta finishing menggunakan clear. Kemasan di kombinasi degan material gravoply pada bagian bawah setiap sisi kemasan.

Alternatif Desain 4 (Victoria's Secret). Desain yang digunakan pada alternatif desain 4 menggunakan bentuk kombinasi poligon dan kotak dengan sistem buka tutup pada bagian atas (Gambar 6). Eksperimen yang digunakan yaitu pewarnaan menggunakan cat tembok water base berwarna pink dan hitam dan finishing menggunakan clear. Kemasan di kombinasi degan material akrilik pada bagian depan dan gravoply pada bagian atas.

Alternatif Desain 5 (Bvlgari Omnia). Desain yang digunakan pada alternatif desain 5 menggunakan bentuk tubuh wanita dengan sistem buka tutup pada bagian samping. Eksperimen yang digunakan yaitu laser pada merk parfum dan pewarnaan menggunakan cat tembok water base berwarna ungu serta finishing menggunakan clear. Kemasan di kombinasikan dengan material gravoply pada bagian sisi depan dan belakang (Gambar 7).

\section{Produk}

Desain yang dipilih adalah Alternatif Desain 4 (Gambar 6) yang menggunakan bentuk kombinasi poligon dan kotak dengan sistem buka tutup pada bagian atas. Kemasan di kombinasi degan material akrilik pada bagian depan dan gravoply pada bagian atas. Sedangkan merk parfum yang dipilih adalah merk parfum bombshell milik Victoria's Secret yang merupakan produk best seller (Gambar 8).

Produk kemasan parfum bombshell Victoria's Secret menggunakan material cork $2 \mathrm{~mm}$ yang dilaminasi 4 lapis dengan dimensi tinggi $16,5 \mathrm{~cm}$, lebar 9,5 cm dan panjang 9,5 cm. Mix material yang 
digunakan adalah mix material menggunakan material akrilik pada bagian depan kemasan dan material gravoply pada bagian penutup kemasan. Sistem buka tutup digunakan pada bagian atas kemasan.

Produk kemasan parfum bombshell Victoria's Secret menggunakan material cork $2 \mathrm{~mm}$ yang dilaminasi 4 lapis dengan dimensi tinggi $16,5 \mathrm{~cm}$, lebar 9,5 cm dan panjang 9,5 cm (Gambar 9). Mix material yang digunakan adalah mix material menggunakan material akrilik pada bagian depan kemasan dan material gravoply pada bagian penutup kemasan. Sistem buka tutup digunakan pada bagian atas kemasan.

Kemasan parfum dapat digunakan langsung menjadi display pada parfum yang ditawarkan. Sehingga kemasan juga mampu menjadi lebih menarik dan memiliki daya saing terhadap kompetitor (Gambar 10).

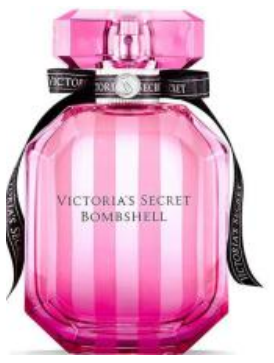

Gambar 8. Parfum bombshell Victoria’s Secret

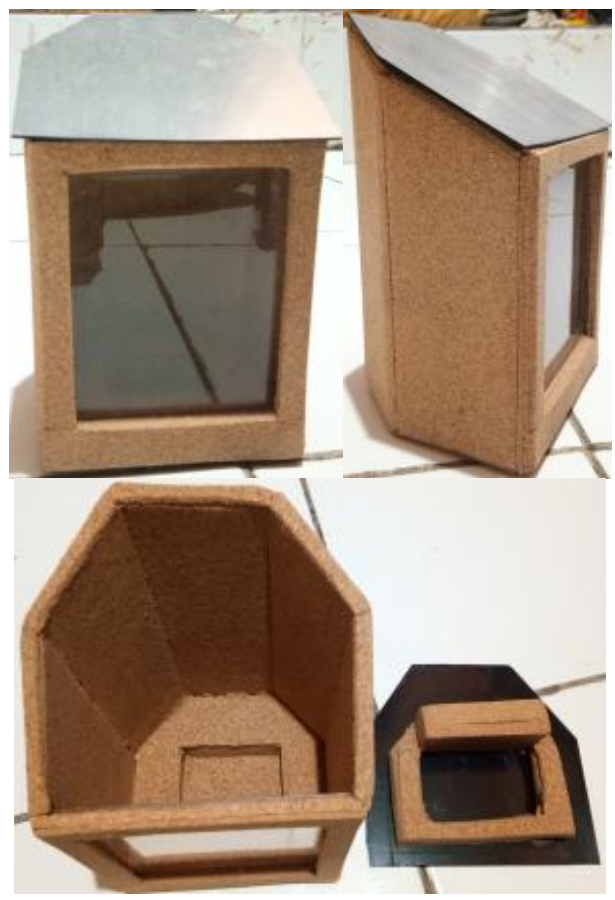

Gambar 9. Produk kemasan Parfum bombshell Victoria’s Secret

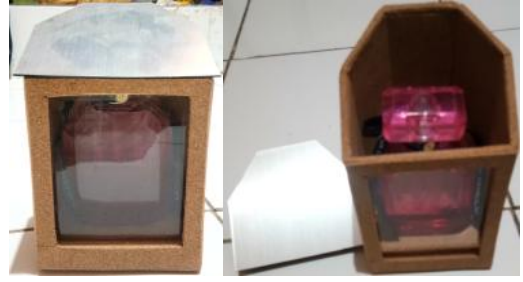

Gambar 10. Display produk kemasan dan parfum bombshell Victoria’s Secret.

\section{Kesimpulan}

Berdasarkan tahapan penelitian yang telah dilakukan, dapat ditarik kesimpulan bahwa :

1. Kemasan parfum yang ada di pasaran hanya berbentuk kotak dan silinder

2. Pemanfaatan material cork di Indonesia yang belum maksimal (Produk coaster dan cork board)

3. Metode penelitian yang digunakan adalah metode eksperimen

4. Proses yang dilakukan pada material cork hingga dapat digunakan menjadi kemasan yaitu pemilahan material, pemotongan material, laminasi, pewarnaan, pengeringan warna, pembentukan pola, penyatuan pola, finishing, eksperimen bentuk dan mix material.

5. Kelebihan dari penelitian ini adalah memaksimalkan kegunaan material cork dan meningkatkan nilai jual parfum serta meningkatkan daya saing.

\section{Daftar pustaka}

Aisyah, Fitri,. (2018). Material M007 - Cork, Si Material Ramah Lingkungan. Retrieved 10 September 2019 from https://diyfabcolab.com/2018/09/14/material-007-cork-simaterial-ramah-lingkungan/

Damai, Sarah,. (2010). Respon Persepsi Terhadap Kemasan Parfum, Fakultas Teknik Industri, Jakarta: Universitas Indonesia.

Gil, Luis,. (2009). Cork Composites. Materials. Vol.2(10) 776789

Hidayat, M. J. (2009). Analisis Industri Budaya Pada Desain Produk Kemasan Makanan Industri Kecil Menengah (1KM). Acintya Jurnal Penelitian Seni Budaya, 1(2).141-151

Nazir, Moh,. (2013). Metode Penelitian. Bogor: Ghalia Indonesia N.N. (2006). Future Of Cork Oak Forest Hangs In The Balance. $\begin{array}{llll}\text { Retrieved } & 10 & \text { September } 2019 \text { from }\end{array}$ https://www.wwf.org.uk/updates/future-cork-oak-forestshangs-balance

Silva, S.P. Sabino, M.A. Fernandes, E.M. Corello, V.M. Boesel, L.F. dan Reis, R.L. (2005). Cork: properties, capabilities and applications. International Materials Review. Vol.50(6) 345365 